\title{
COVID-19 DISSEMINATION ASSESSMENT THROUGH NATURAL VENTILATION IN HOSPITAL PATIENT ROOM BY CFD ANALYSIS
}

\author{
Mohammadhossein Ghasempourabadi ${ }^{1}$, Hossein Hassanzadeh², \\ Shaghayegh Shahrigharahkoshan ${ }^{3}$, Masoume Taraz ${ }^{4}$ \\ 1 Research Scholar, Laval University, Quebec, Canada \\ 2 Department of Chemical Engineering, Laval University, Quebec, Canada \\ ${ }^{3}$ Department of Medicine, Laval University, Quebec, Canada \\ ${ }^{4}$ Department of Architecture and Urban Planning, Faculty of Fine Arts, Tehran
}

Corresponding author: ms.taraz@yahoo.com

\begin{tabular}{cccc} 
& \multicolumn{3}{c}{ Article History: } \\
Received: 14 January & Revised: 28 March & Accepted: 30 April & Available online: 14 Mei \\
2021 & 2021 & 2021 & 2021
\end{tabular}

\begin{abstract}
This paper studies the effect of natural ventilation on the spread of the COVID-19 virus from a patient room to an adjacent room with the help of airflow. The importance of this study is since COVID-19 virus contamination can easily transfer with the airflow from one room to the next room or adjacent corridor. This paper aims to determine the effect of natural ventilation on the contamination of the spaces next to the COVID-19 patients' room.

For this evaluation, we have used mechanical modelling and CFD simulation to evaluate the effect of natural ventilation on the transmission of COVID-19 with the airflow from a contaminated space to a clean space. During this study, we have calibrated the CFD model using one actual case, that was studied in a wind tunnel, and verified the modified model with the actual existing case. The simulated CFD model showed a reasonable accuracy for the prediction of ventilation in indoor spaces.

Results showing the room geometries with air inlet/outlet that positioned at either bottom or top of the room will result in less COVID contamination dissemination through natural ventilation. In addition, in case of having the inlet/outlet in middle and positioning face to face and as well in the case of having max natural air velocity, the maximum contamination will exhaust from the space.
\end{abstract}

Keywords - CFD, contamination dissemination, COVID-19, Hospital Room, Natural Ventilation.

\section{Introduction}

In resource-limited settings, natural ventilation has advantages over mechanical ventilation in the fight against the institutional transmission of airborne infections. While well-maintained negativepressure isolation facilities are the optimal standard of care for infectious respiratory patients. However, they are too costly for many limited-resource settings and are restricted to small high-risk areas of health care settings, neglecting many important areas of potential transmission such as emergency departments and waiting rooms (Granich et al, 1999). While in the case of airborne disease transmission of airborne infections to staff, relatives, and other patients are even more common in the developing world, where health care facilities may disseminate every infection they are attempting to control. In resource-limited settings lacking negative- pressure respiratory isolation, natural ventilation by opening windows is recommended (Escombe et al, 2007). Dilutional 
ventilation with fresh air becomes critical for airborne infection control whenever infectious and susceptible people share air space without the use of particulate respirators, such as in waiting rooms, outpatient clinics, emergency departments, shared wards, and investigation suites (Granich et al, 1999).

Because at present, little is known about the aerodynamic characteristics and transmission pathways of SARS-CoV-2 in aerosols; (Liu et al, 2020) Also there are more pieces of evidence indicating evidence that the virus can also be transmitted by inhalation of microscopic droplets (i.e. aerosols) at short-to-medium range because the virus has been found in small aerosols that can remain in the air for hours, and it has been shown to maintain viability in such aerosols (Asadi et al, 2020; Liu et al, 2020; Van Doremalen et al, 2020) There is sufficient evidence that the Corona Virus can remain alive in the air with a half-life on the order of $1 \mathrm{~h}$. Aerosol transmission of SARSCoV-2 remains viable and infectious in aerosols for hours and on surfaces up to days (Doremalen et al, 2020). Considering the fact that aerosol transmission has been suggested to be an additional, yet important pathway, based on clinical observations in confined spaces (Offord, 2020).

\section{Natural ventilation}

Natural ventilation strategies refer to different forms of drawing air into the building and extracting it from the building (Wood and Salib, 2013). Natural ventilation (NV) is one of the beneficial ways to ameliorate the indoor air quality while it has the potential to diminish the rate of energy usage for cooling the building (Zhai et al, 2015).

There is a consensus on categorizing these methods which are presented here based on the papers skimmed. The benefits of natural ventilation are apparent for a human being because they are familiar with some of them in their vernacular architecture. Lots of studies have been carried out and proved their reconcilable evidence. The figure 1 illustrates the relationship between air pollution in indoor space with airflow rate in which it is clear that there is a direct relationship between these two features (Wood and Salib, 2013).

Some studies show that in buildings that use natural ventilation fewer symptoms have been reported in comparison with the buildings which use mechanical ventilation (Emmerich et al, 2001).

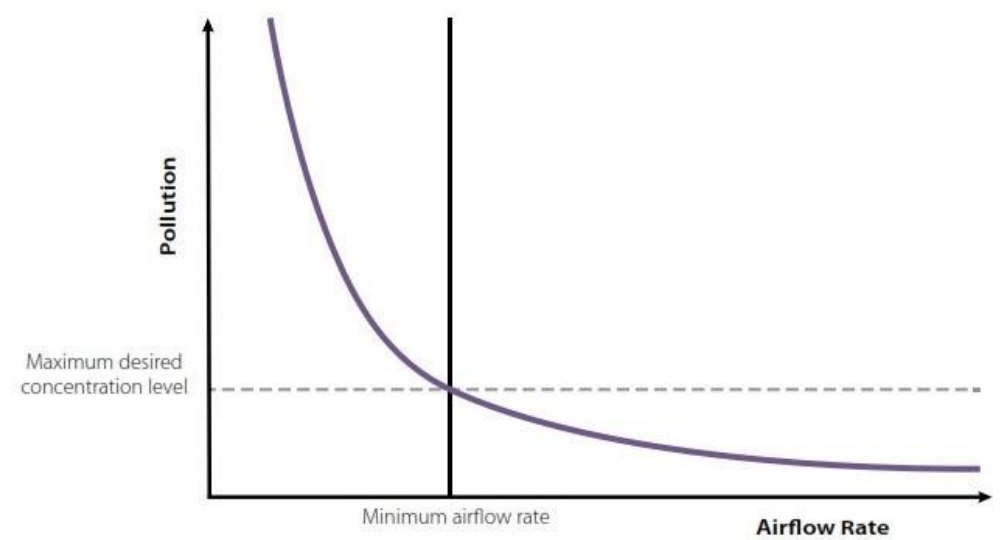

Figure 1: Natural ventilation for indoor air quality showing the relation of pollution level to the airflow rate

Source: Wood and Salib, 2013

\section{The principals of natural ventilation}

Pressure differences across envelope openings are the key feature based on it the strategies of natural ventilation are evolved. These pressure differences are caused by wind, differences between indoor and outdoor air temperature, and the combination of both. Hence, they can be categorized as wind-induced and buoyancy-induced ventilation (Wood and Salib, 2013).

The same classification has been proposed by Emmerich et al. in his paper by a small difference. In his paper, he has categorized natural ventilation strategies in 3 different approaches (Table 1) and indicates that most of the hybrid systems are combinations of these 3 main approaches to natural ventilation:

- Wind-driven cross ventilation,

- Buoyancy-driven stack ventilation, and

- Single-sided ventilation (Emmerich et al, 2001). 
Table 1: natural ventilation strategies

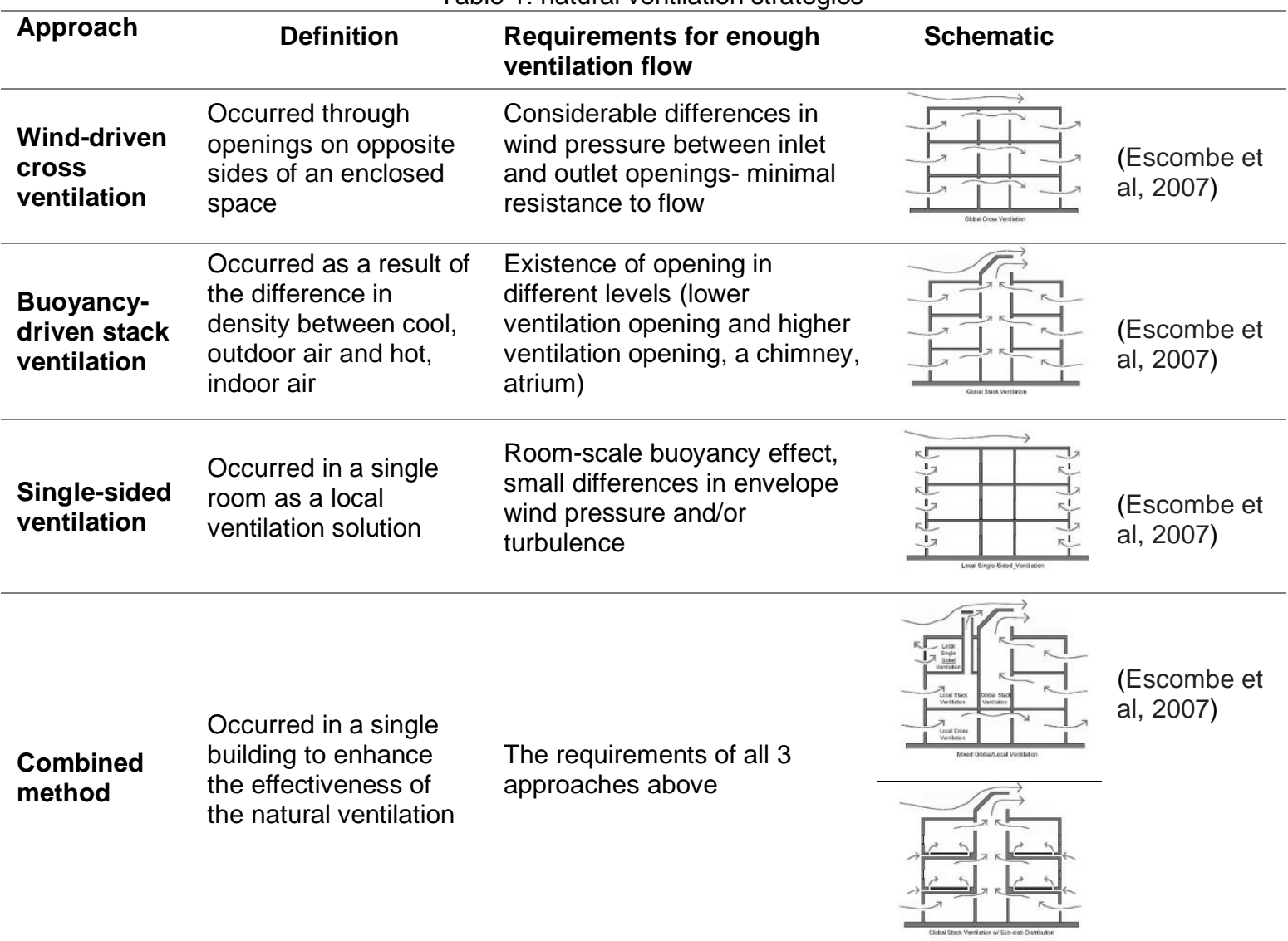

Irving and Clements-Croome (Irving and Clements-Croome, 2005) in their paper summarize the natural ventilation strategies based on the layout of the building (Table 2). The mentioned paper provides the schematic of any kind of natural ventilation form and the proper rate of its effectiveness (Irving and Clements-Croome, 2005). the mentioned table is completed thanks to findings obtained from Chenari et al paper (Chenari et al, 2016).

Table 2: The natural ventilation strategies based on the layout of the building

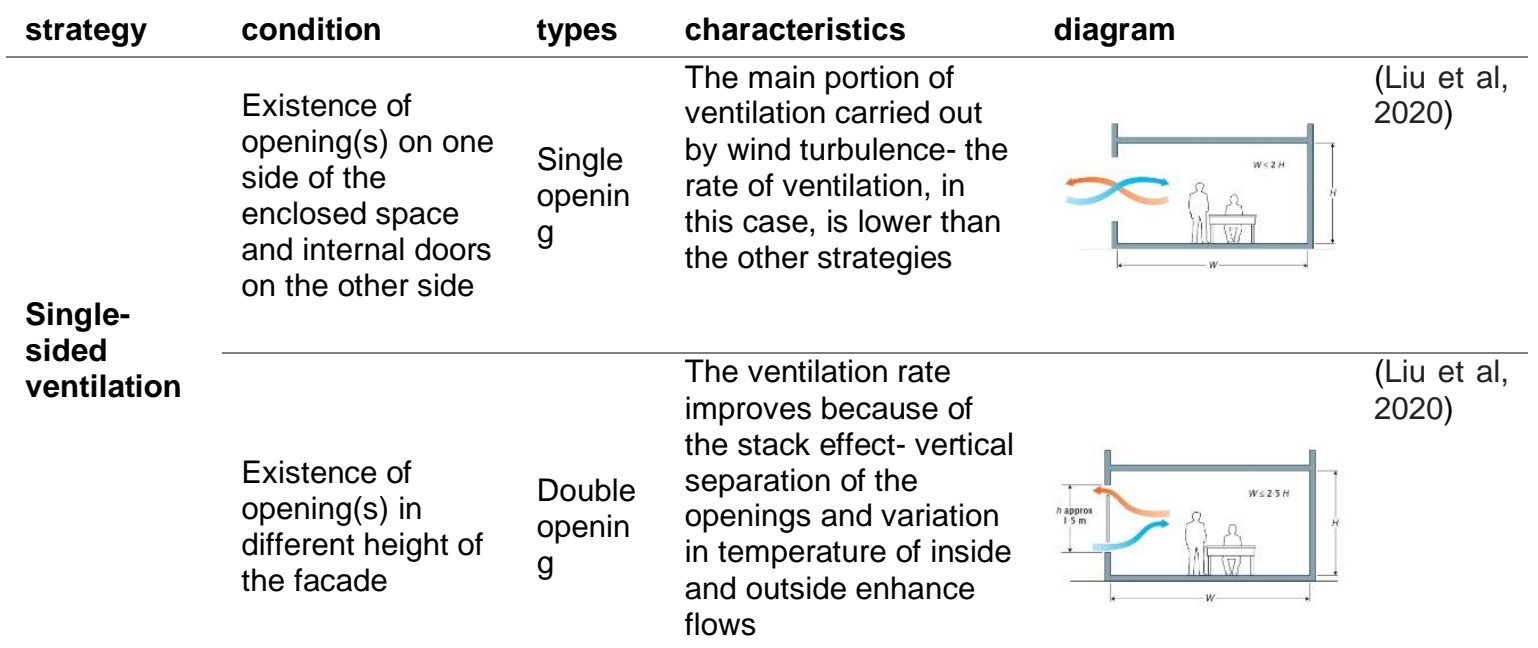




\begin{tabular}{llll}
\hline strategy & condition & types & characteristics \\
$\begin{array}{l}\text { Cross } \\
\text { ventilation }\end{array}$ & $\begin{array}{l}\text { Openings are on } \\
\text { both sides of the } \\
\text { space }\end{array}$ & $-\begin{array}{l}\text { This case is driven by } \\
\text { wind, but it can be } \\
\text { driven by density } \\
\text { differences in an } \\
\text { attached vertical } \\
\text { chimney }\end{array}$ \\
chical
\end{tabular}

Comparison between buildings that use natural ventilation and the ones which use hybrid ventilation shows that in the region with enough wind speed for cross-ventilation, natural ventilation surpasses the hybrid system while in the region without this feature hybrid systems work better than natural ones. Hybrid systems can be categorized into 3 main groups:

- Natural and mechanical ventilation,

- Fan-assisted natural ventilation,

- Stack and wind-assisted mechanical ventilation.

These methods can be used separately or as a combination (Chenari et al, 2016).

\section{The necessity of investigation of natural ventilation}

Based on a review study (Cao et al, 2014). There is a considerable relationship between the ventilation rate and the health of the occupants. The mentioned study refers to the association of air movement in the building with the spread of infection such as measles, tuberculosis, chickenpox, influenza, smallpox and SARS. This paper which states that "there is a lack of evidence in investigating the effect of the airflow distribution methods on the quality of the indoor air which influence the spread of respiratory disease" focuses on the mentioned gap and tries to meet the need for comprehensive literature review in this field (Cao et al, 2014). Also, opportunistic airborne transmission usually occurs during aerosol-generating medical procedures (Christian et al, 2004).

This comprehensive research indicates that there is no quantified evidence related to the association of the airflow rate and spread of infection in gathering spaces like schools, offices, etc. and it needs more studies (Behne,1999). An air-flow pattern in the ventilated room is categorized into two main types: mixing ventilation, displacement ventilation (see figure 2). In mixing ventilation, the process of ventilating is in the way the whole air of the room is completely mixed and the concentration of contaminants in the entire room is the same.

Displacement ventilation works by buoyancy forces as the cool, fresh air tends to stay at a lower level and the hot air tends to go up (see figure 3). This process makes airflow in enclosed spaces.

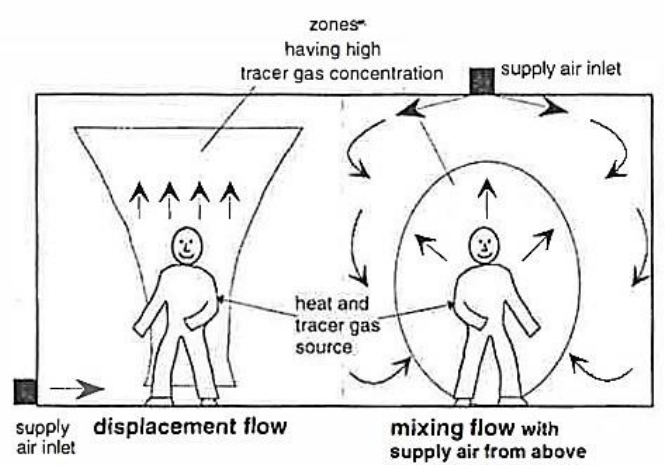

Figure 2: spreading of tracer gas near the manikins being both the heat and tracer gas source, with displacement flow and mixing flow Source: Behne,1999 


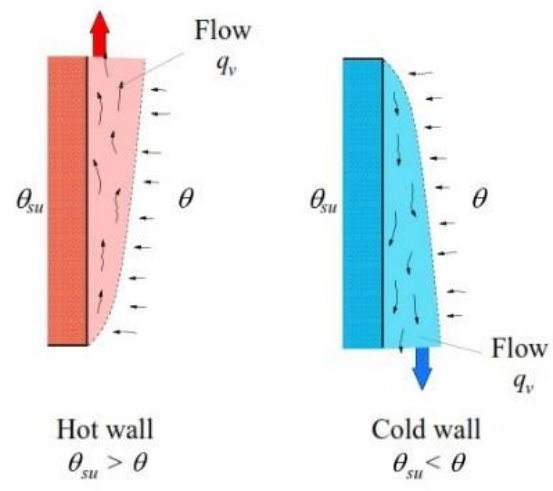

Figure 3: logic of convection flows Source: Skistad et al, 2002

\section{Research Method}

In this work, a three-dimensional numerical scheme using the Computational Fluid Dynamics (CFD) method was developed to analyze natural ventilation flow behavior within the specified rooms, and the accuracy of these numerical simulations was verified against literature results with experimental data (Tominaga and Blocken, 2015; Ramponi and Blocken, 2012). During this study, we have calibrated the CFD model using one actual case, that was studied in a wind tunnel, and verified the modified model with the actual existing case. The simulated CFD model showed a reasonable accuracy for the prediction of ventilation in indoor spaces. After verification, sets of numerical simulations were conducted to analyze the critical parameters to find an optimum operating condition.

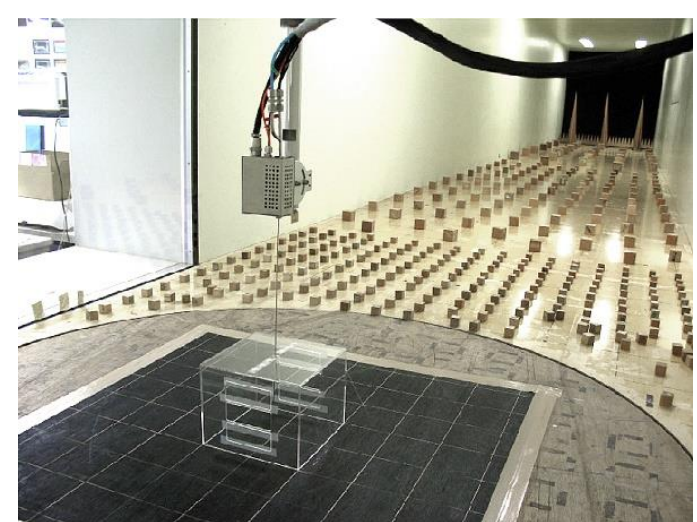

Figure 4: wind-tunnel experiment of the base room model Source: Tominaga and Blocken, 2015

Following, a 3D model using the CFD method assuming Eulerian-Eulerian multiphase flow was implemented to predict fluids distribution in the system. Accordingly, the existence of two main fluid phases is assumed: a) continuous phase (air); b) displaced phase (contamination). In this study, we assumed that the mixture of COVID-19 virus and air is a contamination phase.

Therefore, for this study we have considered the three following geometries of the patient room and its adjacent rooms:

- Geometry I: Two adjacent rooms with a door in between, and two windows (as fresh air inlet and outlet) are positioned face to face.

- Geometry II: Two adjacent rooms with a door in between, the inlet positioned at top of the patient room and the outlet positioned at the bottom of the adjacent room.

- Geometry III: Two adjacent rooms with a door in between, the inlet positioned at the bottom of the patient room and the outlet positioned at the top of the adjacent room. 


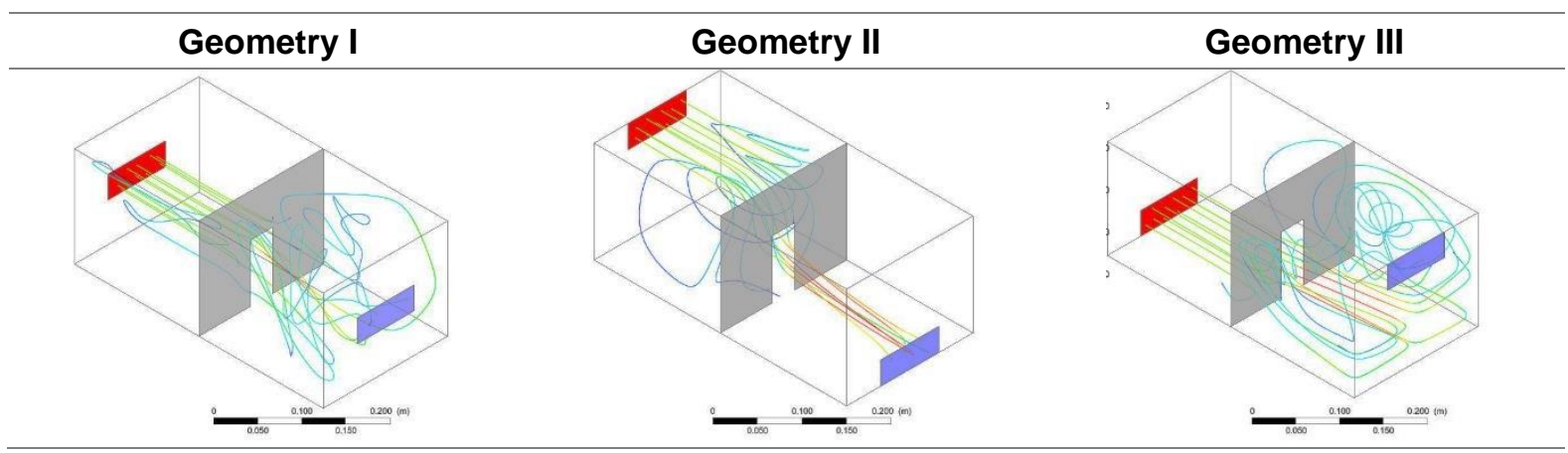

The simplified layouts of the room set are illustrated in Figure 5. In the hospital spaces, this room configuration can be considered in two possible plans. First, and most common, is to have a patient room adjacent to a corridor (figure $5 b$ ). In this situation, the contamination can easily spread between the patient room and the corridor, and within the corridor to the other spaces. In a similar situation, when two patients' rooms are adjacent, airflow can transmit viral contamination like COVID-19 to the next patient room (figure 5a).

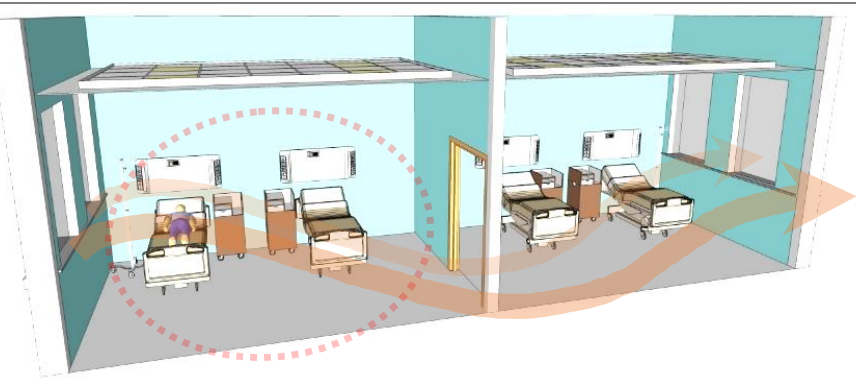

a) Two adjacent patients' room

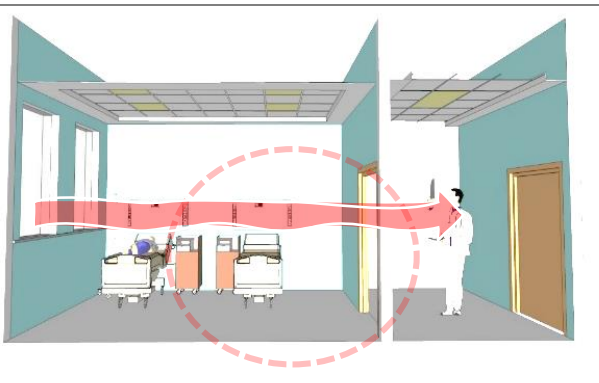

b) A patient room next to the corridor

Figure 5: Hospital room with an adjacent space next to a patient room

In this regard, ANSYS Fluent software has been employed as a modelling tool. The governing equations are explained are as follows (Yan et al, 2020) (note that the subscripts "a" and " $\mathrm{c}$ " indicate the air and contamination phases, respectively):

\section{Continuity equation:}

$$
\begin{aligned}
& \frac{\partial}{\partial t}\left(\alpha_{a} \rho_{a}\right)+\nabla \cdot\left(\alpha_{a} \rho_{a} \overrightarrow{v_{a}}\right)=0 \\
& \alpha_{a}+\alpha_{c}=1
\end{aligned}
$$

Momentum equation: (for each phase)

$$
\begin{aligned}
& \frac{\partial}{\partial t}(\alpha \rho \vec{v})+\nabla \cdot\left(\alpha \rho \overrightarrow{v_{i}} \overrightarrow{v_{j}}\right)=-\alpha \nabla P+\nabla \cdot \bar{\tau}+\alpha \rho \vec{g} \\
& =\bar{\tau}=\alpha \mu\left(\nabla \vec{v}+\nabla \vec{v}^{T}\right)+\alpha\left(\lambda-\frac{2}{3} \mu\right) \nabla \cdot \vec{v} \bar{I}
\end{aligned}
$$

For solving the required equations, different procedures and algorithms were implemented (van Hooff et al, 2017; Mahdavinejad et al, 2013). The pressure-velocity equations were coupled using the SIMPLE (Semi-Implicit Method for Pressure-Linked Equations) algorithm. Besides, momentum, volume fraction, and pressure equations were discretized using second-order upwind, QUICK (Quadratic Upstream Interpolation for Convective Kinematics), and least squares cell-based, respectively.

And to be able to see the effect of airflow in transmitting the contaminated air volume, three different air inlet velocities are implemented for the three above mentioned room geometries.

In total, we have considered the cases based on the following factors ( 30 cases): 


\begin{tabular}{lcl}
\hline Velocity & Natural air attack angle & Geometry \\
\hline $\mathrm{V} 1=4 \mathrm{~m} / \mathrm{s}$ & +45 & $\mathrm{I}=$ inlet/outlet in middle \\
\hline $\mathrm{V} 2=2 \mathrm{~m} / \mathrm{s}$ & +90 & $\mathrm{II}=$ inlet/top, outlet/bottom \\
\hline $\mathrm{V} 3=0.5 \mathrm{~m} / \mathrm{s}$ & +135 & $\mathrm{III}=$ inlet/bottom, outlet/top \\
\hline
\end{tabular}
following:

And to be able to compare different cases together, the reference time $(T)$ is defined as the

$$
\begin{aligned}
& \mathrm{T}=\text { The time that the contamination phase touches the outlet window, where the inlet } \\
& \text { velocity has the lowest value. } \\
& \text { (Geometry }=\mathrm{I} \text {, Attack angle }=+90 \text { and Velocity }=0.5 \mathrm{~m} / \mathrm{s} \text { ) }
\end{aligned}
$$

\section{Results and discussion}

\section{Effect of windows (inlet/outlet) positioning}

By processing the CFD analysis for all of the cases, considering all the three different velocities of natural ventilation as previously defined, the spreading patterns of contamination phase are shown in figure 6 . Also, the percentage of contamination (ratio of contamination volume to the total volume of rooms) is indicated separately in the results in table 4.

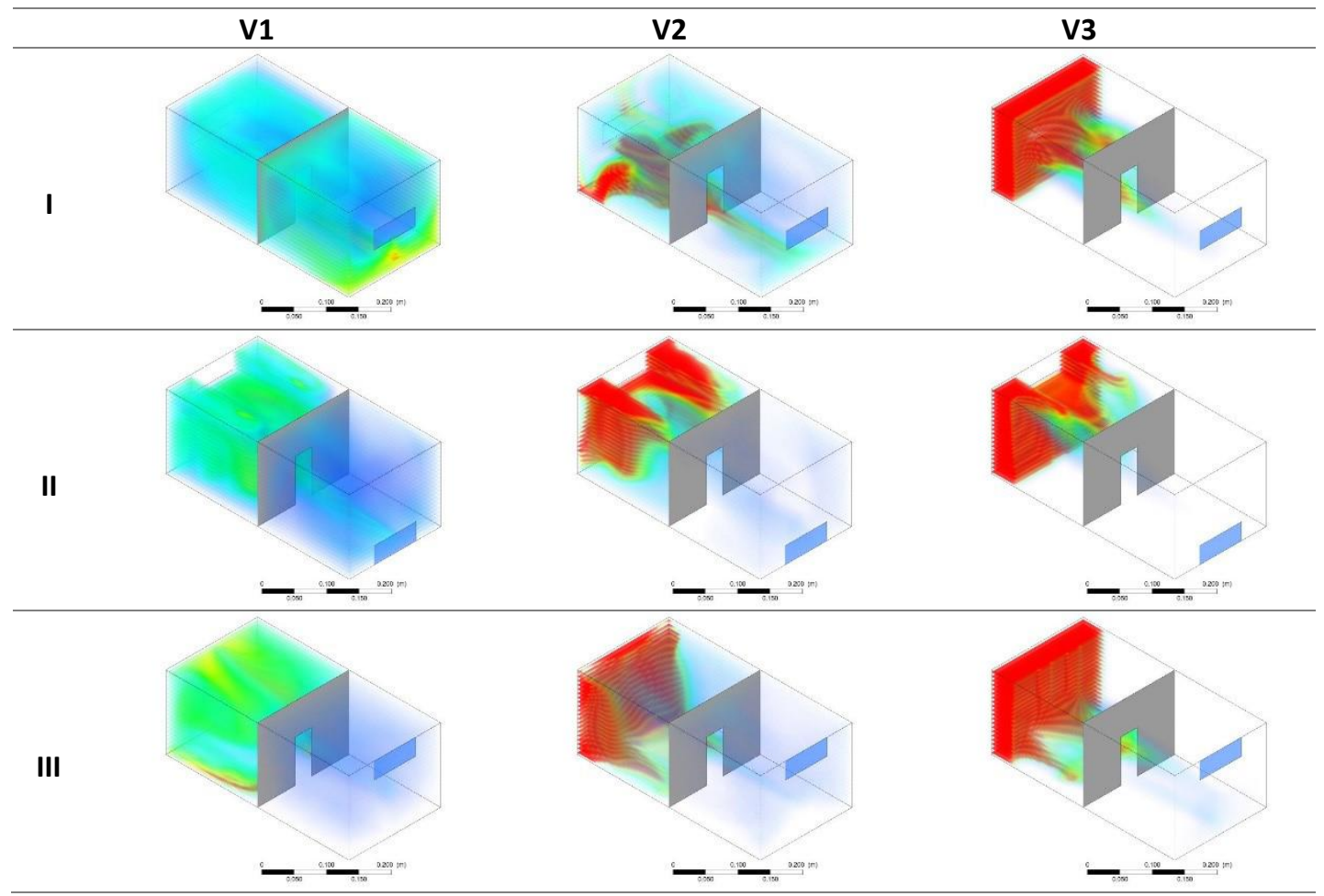

Figure 6: Result of 3D CFD natural airflow simulation of the two adjacent rooms.

\section{Estimated risk of COVID-19 contamination by natural ventilation}

In this scenario, the aim is to investigate the amount of contamination in the adjacent space next to an infected patient room with the presence of COVID-19 patients. To be able to predict such contamination with the help of airflow, as the first step we have simulated our base model (Geometry $=\mathrm{I}$, Attack angle $=+90$ and Velocity $=4 \mathrm{~m} / \mathrm{s}$ ) with natural airflow exposure over the time evolution. 


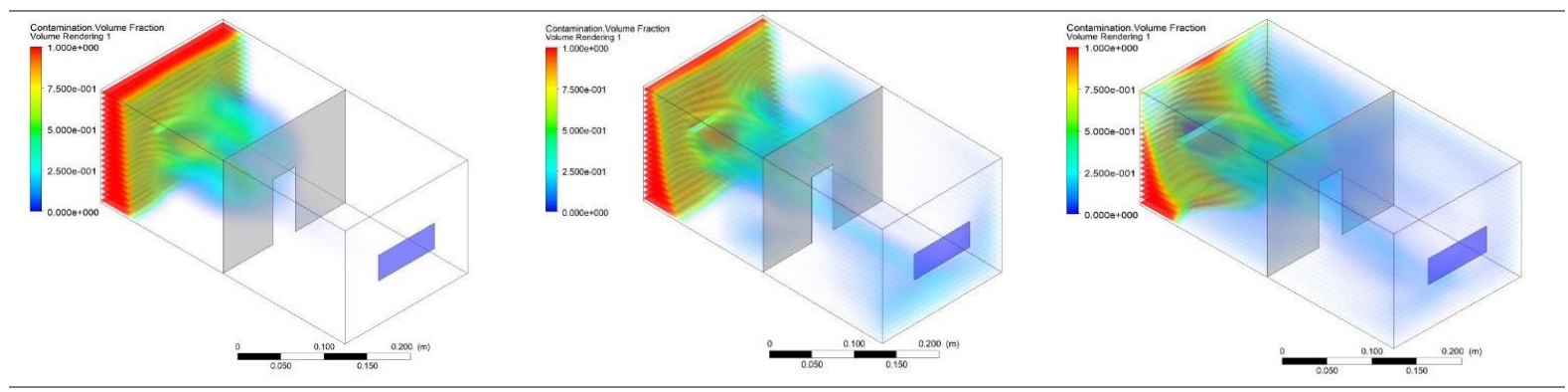

a) $\mathrm{t}=1 / 6 \mathrm{~T}$

b) $t=2 / 6 \mathrm{~T}$

c) $\mathrm{t}=3 / 6 \mathrm{~T}$

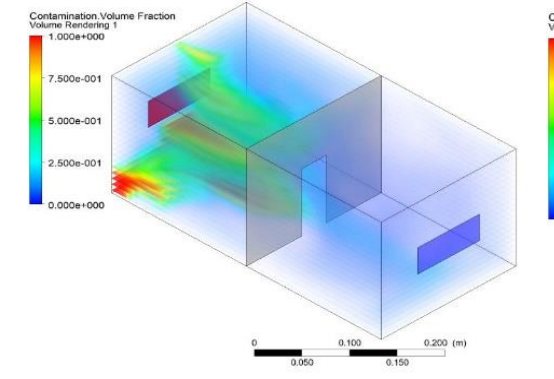

d) $\mathrm{t}=4 / 6 \mathrm{~T}$

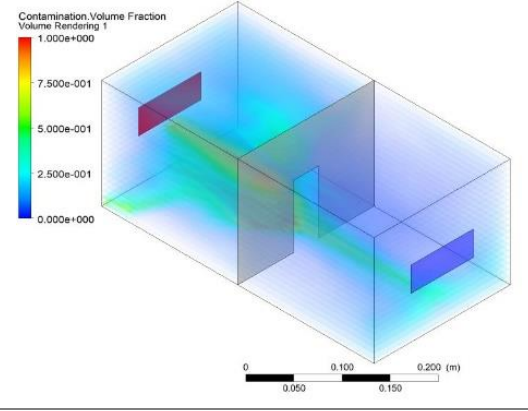

e) $\mathrm{t}=5 / 6 \mathrm{~T}$

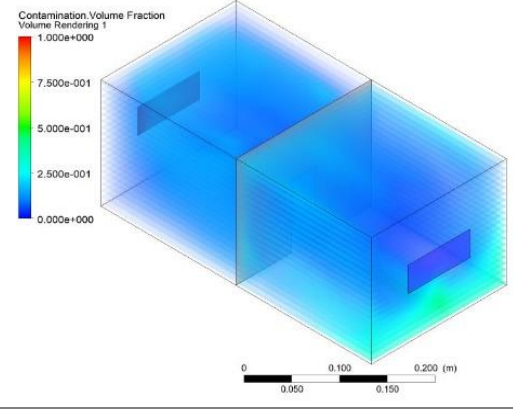

f) $t=6 / 6 \mathrm{~T}$

Figure 7: Contamination dissemination simulated for the geometry I with an attack angle of +90 and the velocity of $4 \mathrm{~m} / \mathrm{s}$ by time evolution.

Based on figure7, the COVID contamination dissemination is obvious by time evolution. With having natural ventilation, the flow makes some turbulence and air mixing effects in the patient's room (figure 7a) and then the contamination penetrates the adjacent room by making turbulences and air mixing flows just nearby the outlet window. (figure $7 \mathrm{~b}$ ) and this mixing effect continues till the whole second space is contaminated by the flow, to the point that both the patient room and adjacent room are fully contaminated (figure $7 \mathrm{f}$ )

To be able to evaluate better the airflow behavior and its dissemination of contamination, we have analyzed the natural ventilation in two extreme velocities for all three geometries. As depicted in Figure 8, the max velocity, make a quick swift of contamination from the patient room to the adjacent room for I and II geometries. But when the inlet is at the bottom and the outlet is at the top of the adjacent room, even in the max velocity the contamination dissemination is less than the other two cases. Making the geometry III, as the optimum response in the cities with higher natural wind velocities to reduce contamination dissemination from one space to another (figure 8a). While in studying the case with minimum velocity the lowest contamination dissemination is related to geometry II (figure8b). Therefore, for the cities with lower natural wind velocities, this should be an optimum case for having natural ventilation to minimize COVID dissemination from one space to another.

$$
\text { I II III }
$$

a) Max Air Velocity $(\mathrm{t}=6 / 6 \mathrm{~T})$
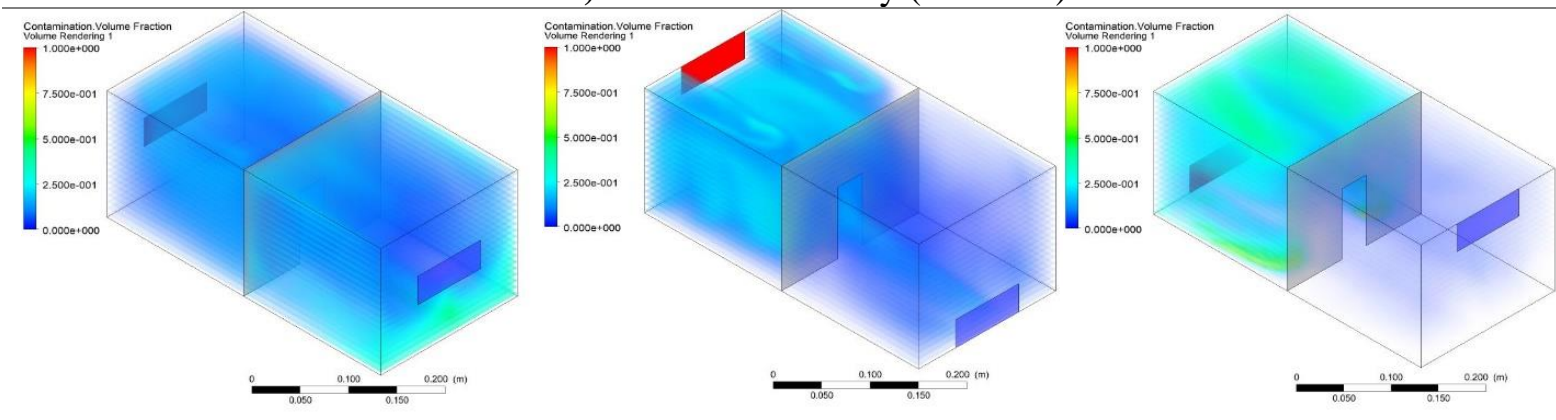


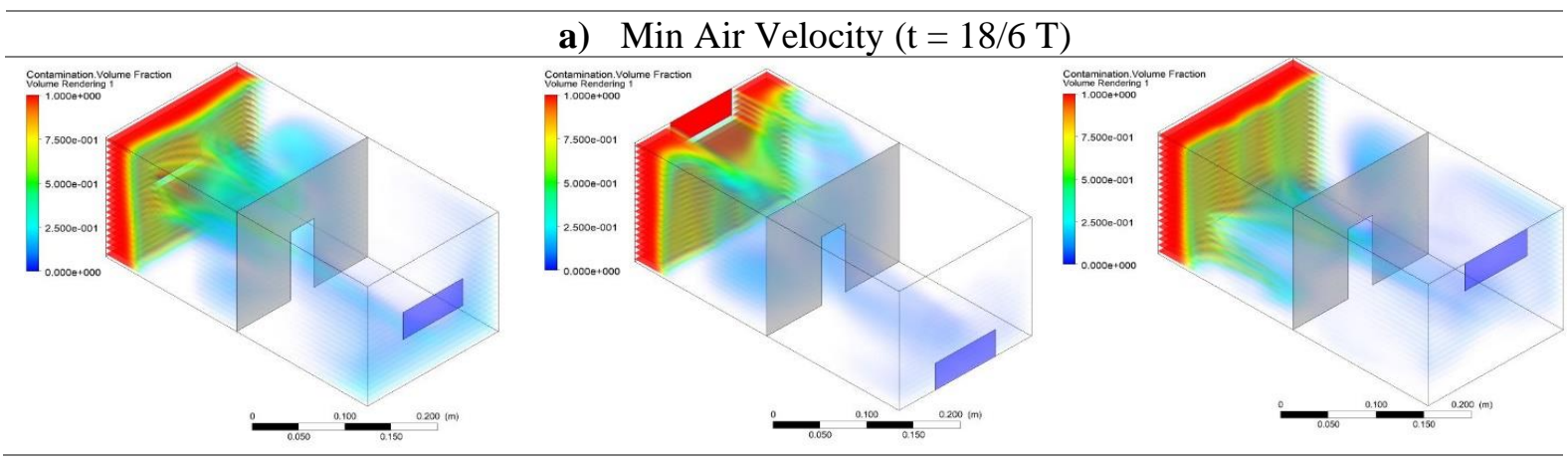

Figure 8: Extreme velocity values shows the different dissemination by natural ventilation

Evaluation of COVID contamination dissemination in the adjacent room to the patient room We have summarized the results for all geometries in the following table by specifying the natural wind velocities for each case. The results are representing the volume fraction percentage of contamination in each case.

Table 4: The results for all geometries

\begin{tabular}{|c|c|c|c|c|}
\hline & & $\begin{array}{l}\text { Patient } \\
\text { room }\end{array}$ & $\begin{array}{l}\text { Adjacent } \\
\text { room }\end{array}$ & $\begin{array}{c}\text { Exhausted } \\
\text { contamination }\end{array}$ \\
\hline \multirow{3}{*}{ I } & V1 & $40 \%$ & $36 \%$ & $24 \%$ \\
\hline & V2 & $78.8 \%$ & $17.2 \%$ & $4 \%$ \\
\hline & V3 & $98.5 \%$ & $1.5 \%$ & $0 \%$ \\
\hline \multirow{3}{*}{ II } & $\mathrm{V} 1$ & $64 \%$ & $14 \%$ & $22 \%$ \\
\hline & V2 & $84 \%$ & $5 \%$ & $11 \%$ \\
\hline & V3 & $94.5 \%$ & $3.5 \%$ & $2 \%$ \\
\hline \multirow{3}{*}{ III } & $\mathrm{V} 1$ & $74.5 \%$ & $10.5 \%$ & $15 \%$ \\
\hline & V2 & $80 \%$ & $14 \%$ & $6 \%$ \\
\hline & V3 & $93.5 \%$ & $5.5 \%$ & $1 \%$ \\
\hline
\end{tabular}

Considering all the geometries and velocities together for the three scenarios of a) patient room, b) adjacent room and c) exhausted contamination, we can illustrate the results in the flowing format as a graph (see figure 9).

Based on our results, for the patient's room, the lowest contamination concentration will result by geometry I and V1 (max velocity) and the highest contamination results in the same geometry with having V3 (min velocity). While in the adjacent room, the results are vice versa. The highest contamination is by having the geometry I and V1 and the lowest report is the geometry I and V3. And in case of having the inlet/outlet in middle positioning face to face, in case of having max natural air velocity, the maximum contamination will exhaust from the space.

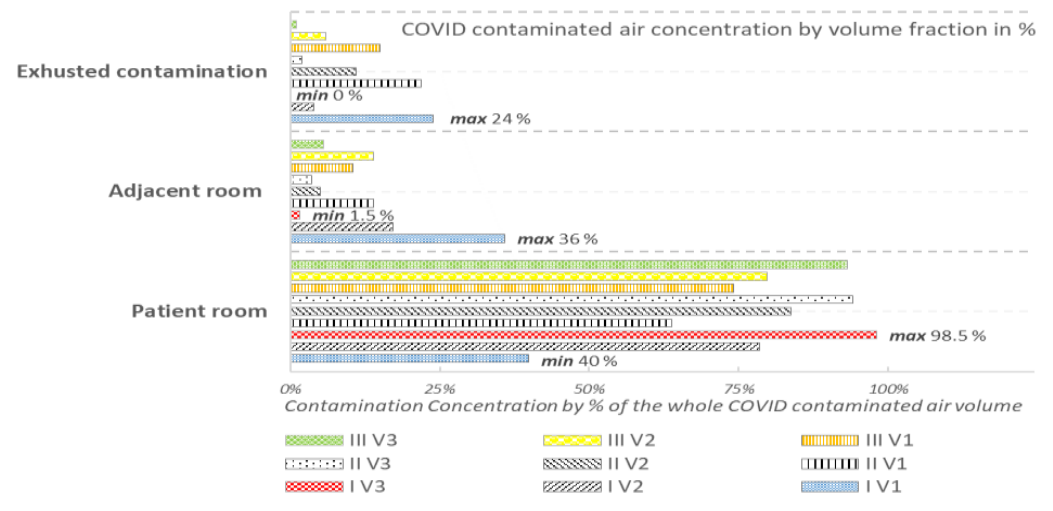

Figure 9: Contamination percentage for each space considering all scenarios 


\section{Effects of airflow direction on contamination dissemination}

It is worth mentioning that we have investigated the effect of the natural air inlet angle for air penetration into this space as well. This effect is studied in three different inlet angles of $+45,+90,+135$ degrees from the window axis.

In the table below, the red spots are showing the concentration of the contaminated air with the virus. It is obvious that in general, the inlet angle of +45 and +135 have less amount of contaminated air in both simulated rooms. The reason is due to the effect of mixing the fresh air and the contaminated air in the first space. It means that when the inlet angle is not perpendicular to the wall, there is more chance of fixation of the fresh air and contaminated air, and this will lead to removing the contamination with the airflow from both spaces.

This should be considered that if the reason for using the natural ventilation in the patient's room is just to remove the contaminated air, the direct angle of +90 is the worst scenario since it causes the minimum air mixing and causes maximum air turbulence at the room that stock the contamination in the space. Therefore, if the direction of the inlet remains on +90 , the effect of positioning of the inlet/outlet is minimized and we have the highest of contamination remaining in the space. For sure there is a need for a different study to find the optimum angle of airflow to minimize the contamination in the space.

\begin{tabular}{l|c|ccc}
\hline \multicolumn{1}{c}{ Orientation all 9 cases } & II & III \\
\hline & I & & \\
\hline
\end{tabular}

\section{Conclusion}

The chart below is revealing the main conclusion on the results. As in total, we considered three different inlet wind velocities for our three different inlet/outlet positions in the patient's room, at the end we came up with the nine different situations for the contamination of the space adjacent to the patient's room. To better understand this effect, we have isolated the flow and the volume of the contamination in this space and presented the results in the chart below.

As it is screening in the results, the higher inlet velocity leads to the higher amount of contamination in the second space; similarly, the lower the inlet velocity leads to the lower contamination in the second space.

Since the total amount of contaminated air volume by COVID-19 virus is presumed fixed, by mixing air in two space and ventilation from one space to another, the concentration of contamination directly affects the other space as well. Meaning that whenever we have a surge in contamination in one space in the other space the results will be in contrast.

For the adjacent room, as portrayed in figure 10, the best-case scenario is having the low velocities. Meaning that V3 in all geometries resulting in less contamination transmission from the patient's room. Therefore, this should be as the general rule that minimum ventilation rate results in less dissemination regardless of input/output positioning. This is indicating that in such situation there is the minimum record of exhausted contamination from the both spaces. So, there is a need for special attention that although with lowering the ventilation rate and inlet velocity we can control the dissemination, but low velocities results in fewer exhaustion from contaminated spaces and this results in accumulation of contamination in the patient room. 
The worst-case scenarios for COVID dissemination from one space to another, happen when the velocities are at the highest possible rate. Meaning that the higher the ventilation rate, the higher dissemination from one space to another. In this situation is advised to use air filtration or direct exhaust of the contamination air to outside space to avoid further contamination. This logical since based on figure 11, the extremes values of the adjacent room contamination and exhausted contamination are following the same trends; meaning that the lower the exhausted contamination the lower dissemination and vice versa.

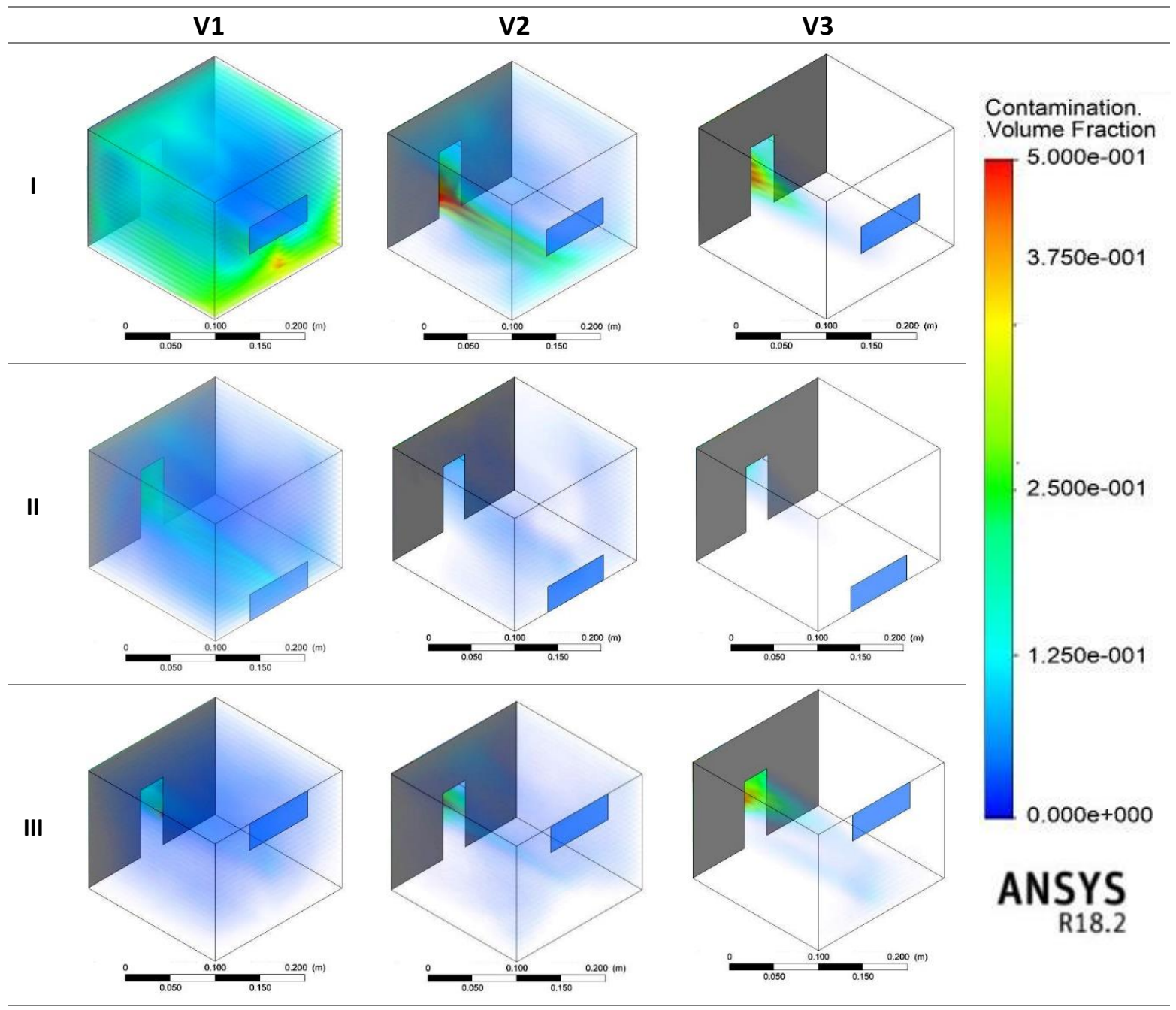

Figure 10: Contamination percentage for each space considering all scenarios

Outcomes are showing that the inlet at the bottom and outlet at the top will consequence in less contamination in the second space at higher inlet velocities. And considering the bottom to top positioning of inlet and outlet for natural ventilation should be a considerable solution in removing the contamination.

Base on figure 11, the best exhaustion is related to geometry I with inlet/outlet face to face of each other. Also having the air inlet at the top of the space will result in better air exhaustion. Also, the extreme values of contamination percentage of the patient room and its adjacent room are opposite of each other due to being connected and having air movement and air mixing effects.

It is important to consider if the purpose of natural ventilation is bringing fresh air to the patient room and exhausting the contamination the higher velocity (V1) and geometry I with faceto-face inlet/ outlet would be the optimum option. And if the purpose of the ventilation is minimizing the contamination dissemination to the adjacent room the lowest velocity (V3) with the air inlet at the bottom of the patient room will be optimum case. 

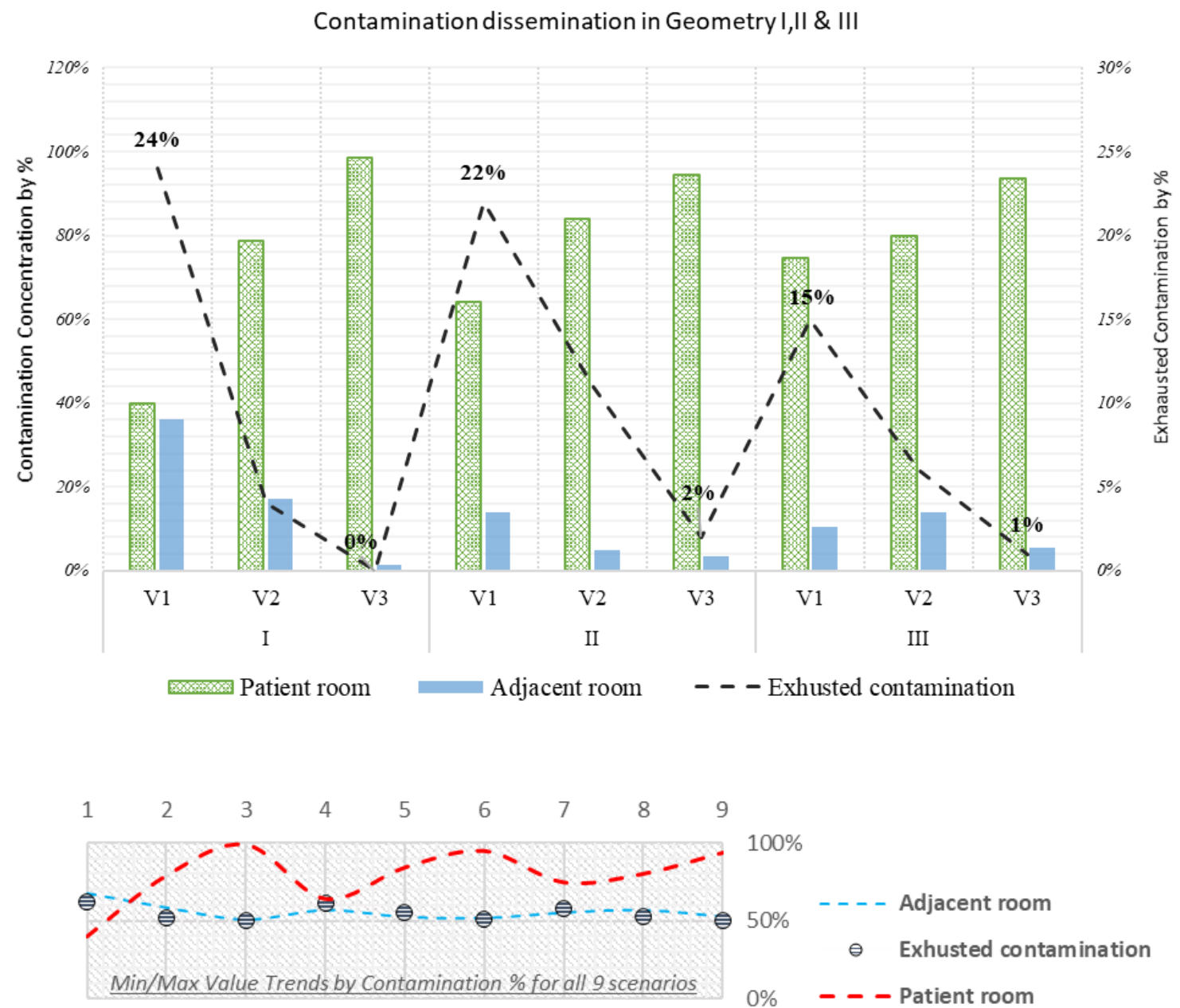

Figure 11: Contamination dissemination for all geometries and scenarios

Besides, lower inlet velocity will cause the minimum contamination transmission to the second space; but the problem, in this case, is that minimizing the inlet velocity, the contaminated air stays at the patient's room and does not leave the space. Also, Results showing the room geometries with air inlet/outlet at positioned at either bottom or top of the room will result in less COVID-19 contamination dissemination through natural ventilation. And in case of having the inlet/outlet in middle positioning face to face, in case of having max natural air velocity, the maximum contamination will exhaust from the space.

\section{References}

Granich, R., Binkin, N. J., Jarvis, W. R., Simone, P. M., Rieder, H. L., Espinal, M. A., ... \& World Health Organization. (1999). Guidelines for the prevention of tuberculosis in health care facilities in resource-limited settings (No. WHO/CDS/TB/99.269). World Health Organization.

Escombe, A. R., Oeser, C. C., Gilman, R. H., Navincopa, M., Ticona, E., Pan, W., ... \& Evans, C. A. (2007). Natural ventilation for the prevention of airborne contagion. PLoS Med, 4(2), e68.

Liu, Y., Ning, Z., Chen, Y., Guo, M., Liu, Y., Gali, N. K., ... \& Lan, K. (2020). Aerodynamic analysis of SARS-CoV-2 in two Wuhan hospitals. Nature, 582(7813), 557-560.

Asadi, S., Bouvier, N., Wexler, A. S., \& Ristenpart, W. D. (2020). The coronavirus pandemic and aerosols: Does COVID-19 transmit via expiratory particles?.

Van Doremalen, N., Bushmaker, T., Morris, D. H., Holbrook, M. G., Gamble, A., Williamson, B. N., ... \& Munster, V. J. (2020). Aerosol and surface stability of SARS-CoV-2 as compared with SARS-CoV-1. New England Journal of Medicine, 382(16), 1564-1567.

Offord C. How COVID-19 is spread. The Scientist https://www. the-scientist. com/newsopinion/how-covid-19-is-spread-67143 (21 February 2020). 2020. 
Wood, A., \& Salib, R. (2013). Natural ventilation in high-rise office buildings, CTBUH technical guides. New York and London: Routledge.

Zhai, Z. J., El Mankibi, M., \& Zoubir, A. (2015). Review of natural ventilation models. Energy Procedia, 78, 2700-2705.

Emmerich, S. J., Dols, W. S., \& Axley, J. W. (2001). Natural ventilation review and plan for design and analysis tools (pp. 1-56). US Department of Commerce, Technology Administration, National Institute of Standards and Technology.

Irving, S., \& Clements-Croome, D. J. (2005). Natural ventilation in non-domestic buildings. Chartered Institution of Building Services Engineers.

Chenari, B., Carrilho, J. D., \& da Silva, M. G. (2016). Towards sustainable, energy-efficient and healthy ventilation strategies in buildings: A review. Renewable and Sustainable Energy Reviews, 59, 1426-1447.

Cao, G., Awbi, H., Yao, R., Fan, Y., Sirén, K., Kosonen, R., \& Zhang, J. J. (2014). A review of the performance of different ventilation and airflow distribution systems in buildings. Building and Environment, 73, 171-186.

Christian, M. D., Loutfy, M., McDonald, L. C., Martinez, K. F., Ofner, M., Wong, T., ... \& SARS Investigation Team. (2004). Possible SARS coronavirus transmission during cardiopulmonary resuscitation. Emerging infectious diseases, 10(2), 287.

Behne, M. (1999). Indoor air quality in rooms with cooled ceilings.: Mixing ventilation or rather displacement ventilation?. Energy and Buildings, 30(2), 155-166.

Skistad, H., Mundt, E., Nielsen, P. V., Hagström, K., \& Railio, J. (2002). Displacement ventilation in non-industrial premises. REHVA Guidebook no. 1. ISBN 82-594-239-3.

Tominaga, Y., \& Blocken, B. (2015). Wind tunnel experiments on cross-ventilation flow of a generic building with contaminant dispersion in unsheltered and sheltered conditions. Building and Environment, 92, 452-461.

Ramponi, R., \& Blocken, B. (2012). CFD simulation of cross-ventilation for a generic isolated building: impact of computational parameters. Building and Environment, 53, 34-48.

Yan, Y., Li, X., \& Ito, K. (2020). Numerical investigation of indoor particulate contaminant transport using the Eulerian-Eulerian and Eulerian-Lagrangian two-phase flow models. Experimental and Computational Multiphase Flow, 2(1), 31-40.

van Hooff, T., Blocken, B., \& Tominaga, Y. (2017). On the accuracy of CFD simulations of crossventilation flows for a generic isolated building: comparison of RANS, LES and experiments. Building and Environment, 114, 148-165.

Mahdavinejad, M., Ghasempoorabadi, M., \& Javanrudi, K. (2013). Numerical Modeling and Experimental Study of Air Flow in theYazdi Wind-Towers. University of science and technology of Iran, 23(1), 17-22.

Mahdavinejad, M., Javanroodi, K., Ghasempoorabadi, M. H., \& Bemanian, M. (2013). Evaluating the efficiency of YAZDI wind tower, an experimental study. Int. J. Archit. Eng. Urban Plan., 23(1), 17-22. 